\title{
Nanocellulose-based Composite Materials for Wastewater Treatment and Waste-oil Remediation
}

\author{
Bingnan Yuan, ${ }^{1}$ Ling Li, ${ }^{2,}$ Vignesh Murugadoss, ${ }^{1}$ Sravanthi Vupputuri, ${ }^{1}$ Jinwu Wang, ${ }^{3, *}$ Nasim Alikhani ${ }^{2}$ and Zhanhu Guo ${ }^{1, *}$
}

\begin{abstract}
This review highlights the latest research studies about the use of lignocellulosic nanocellulose-based composites in the applications of wastewater treatment and waste-oil remediation. Three types of composites are described, including nanocellulose-based aerogels, nanocellulose-based membranes, and new wood-based morph-genetic materials. The fabrication and modification techniques to prepare these composites are introduced. The effectiveness and efficiency of these composites in the adsorption of heavy metal ions, dyes, and micropollutants, separation of oil and water, and catalytic degradation of organic pollutants are discussed, respectively. In addition, the challenges and opportunities of nanocellulose-based composites in these areas and the future research directions of lignocellulosic nanocellulose composites for wastewater treatment and waste-oil remediation are addressed.
\end{abstract}

Keywords: Aerogel; Membrane; Heavy metals; Wastewater treatment; Waste-oil remediation.

Received: 17 June 2020; Accepted: 29 August 2020.

Article type: Review article.

\section{Introduction}

Wastewater and spilled-oil are two major types of liquid wastes that often cause enormous temporary or permanent harm to the environment and ecology if no appropriate treatment is conducted before they enter the land or surface water. Municipal and industrial wastewater contains a large quantity of dissolved or suspended contaminants in water, such as toxic organics and heavy metals. The wastewater effluents are usually treated to remove those dissolved or suspended substances in wastewater treatment plants through practiced methods, such as flotation, coagulation/ precipitation, membrane processes, electrochemical techniques, and ion exchange. ${ }^{[1]}$ In these methods, the precipitation method is a cost-effective method, which adds lime (an alkaline material) from recycled gypsum in wastewater to form metal hydroxide precipitate consisting of cationic heavy metals like $\mathrm{Pb}(\mathrm{II}), \mathrm{Cd}(\mathrm{II}), \mathrm{Cu}(\mathrm{II})$ and $\mathrm{Ni}(\mathrm{II}){ }^{[1]}$ The membrane separation method is another promising

\footnotetext{
${ }^{1}$ Integrated Composites Laboratory (ICL), Department of Chemical and Biomolecular Engineering, University of Tennessee, Knoxville, Tennessee 37996, USA

${ }^{2}$ School of Forest Resources, University of Maine, Orono, ME 04469-5755, USA

${ }^{3}$ USDA Forest Service, Forest Products laboratory, Madison WI 53726, USA

*E-mail:zguo10@utk.edu_(Z.Guo); ling.li@maine.edu (L. Li)
}

solution for filtering the suspended substances in wastewater. ${ }^{[2]}$ However, these methods often employ inorganic or synthetic fossil-based materials derived from nonrenewable natural resources.

Waste-oil in the ocean may come from different sources. The primary source is land drainage and waste disposal, for example, used motor oil. In addition, offshore oil production operations, routine maintenance of ships, and spills or leaks from tank ships are other sources. The remedies of oil spills are classified into physical, chemical, and biological methods In physical methods, sorbent substances in the form of powders, fibers, foams, and fabrics can efficiently remove oily substances from the spilled ocean areas. In recent years, advanced nanotechnology enables to produce low-cost, high adsorption performance nanocellulose-based composite materials, using abundant renewable and sustainable forestry-based lignocellulose resources. ${ }^{[3]}$ The materials include adsorption gels, membranes, and new wood-based morph genetic materials. These emerging materials have great potential to substitute the equivalent fossil-based materials for removing unwanted substances from wastewater and waste-oil to reduce the embodied energy of materials and minimizing the environmental impact.

There are various types of nanocellulose materials according to the origin of raw material, preparation process, 
and morphological structure. These nanocellulose materials have been named variously including nanocellulose, nanocrystalline cellulose (NCC), cellulose nanocrystals (CNCs), cellulose nanofibrils (CNFs), cellulose microfibers, cellulose nanofibers, nanofibrillated cellulose (NFC), microfibrillated cellulose, and combinations of the above..$^{[4-6]}$ It is suggested by the Technical Association of the Pulp and Paper Industry (TAPPI) that cellulose materials can be named with nano-objects and categorized into two main groups: CNFs and CNCs. ${ }^{[7]}$ In this review, several names of nanocellulose materials may be shown in different research studies to represent the same material to keep consistency with the authors. Nanocelulose can be made from various cellulose origins such as bacterial cellulose (BC), tunicates, cotton, and wood.

The goal of this review is to overview the state-of-the-art techniques of fabricating nanocellulose-based (including $\mathrm{CNFs}$ and $\mathrm{CNCs}$ ) composites that can be used as bio-based sorbents or precipitants in wastewater treatment and waste-oil remediation and assessing the role of CNFs and CNCs played in these treatments. The nanocellulose-based composites are present in the forms of aerogel, membrane, and modified wood-based morph genetic materials. In addition, the perspectives on future research about expanding the use of CNFs and CNCs in waste management are discussed.

\section{Fabrication of nanocellulose fibers from lignocellulosic materials}

Wood, as one of the most abundant renewable lignocellulosic-based biomass resources, is a natural polymer material - a natural composite of cellulose fibrils that is strong in tension and embedded in a matrix of cellulose lignin that functions as a binder with hemicellulose filled out the gaps. Cellulose accounts for $40-50 \%$ of the wood components. ${ }^{[8-9]}$ Therefore, wood is one of the best sources for producing cellulose.

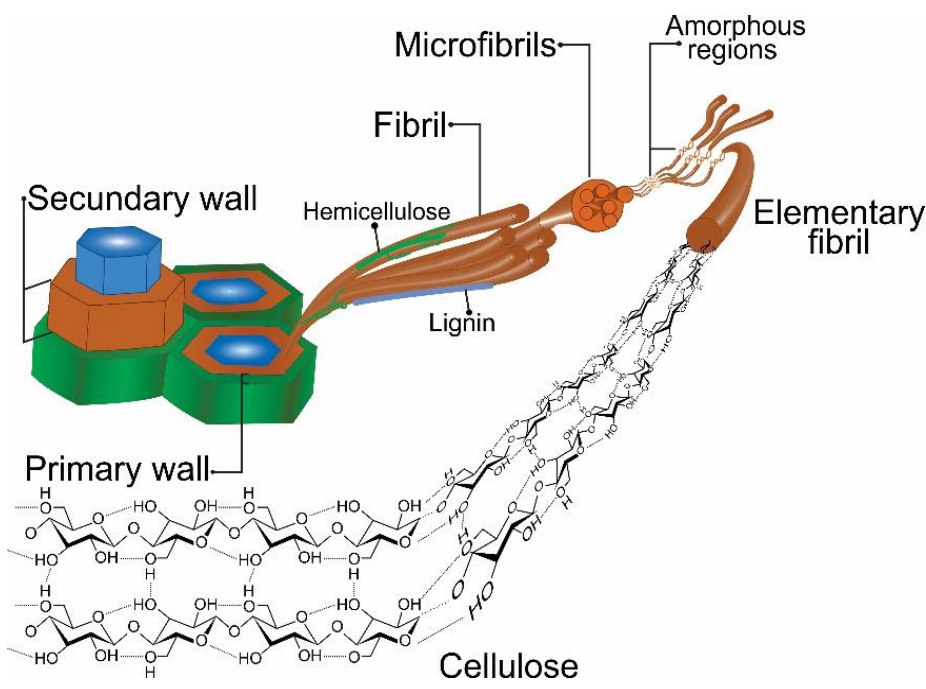

Fig. 1 Hierarchical structure of cellulose. ${ }^{[16]}$ Copyright, 2015

\section{INTECH)}

As shown in Fig. 1, the wood cell wall is composed of microfibrils that, in turn, are composed of elementary fibrils. These fibrils are basic structural units and are about $2-20 \mathrm{~nm}$ in diameter and a few micrometers in length. About 30 to 100 cellulose chains aggregate into an elementary fibril. Each microfibril is a flexible hair strand composed of crystalline regions linked along with non-crystalline areas.

Cellulose fibers used for making CNFs or CNCs are obtained by isolating wood fibers with a sulfite or a Kraft process along with several bleaching processes to remove a majority of lignin and hemicellulose. ${ }^{[10-14]} \mathrm{CNFs}$ can be made by mechanical breakdown of cellulose fibers through high-pressure homogenization, grinding, high-intensity ultrasonication, and/or steam explosion. CNFs are comprised of both amorphous and crystalline structures of cellulose. The diameter of CNFs varies between 5-60 nm, and the length is up to several hundred nanometers, showing a high aspect ratio. Among various processing methods, the 2,2,6,6-tetramethy-iperi-ine-1 oxyl (TEMPO) radical oxidation method is one of the most commonly used methods, which can selectively convert the primary surface hydroxyls in the accessible regions into carboxyl groups and produce TEMPO oxidized CNFs (TOCNFs). ${ }^{[15]}$

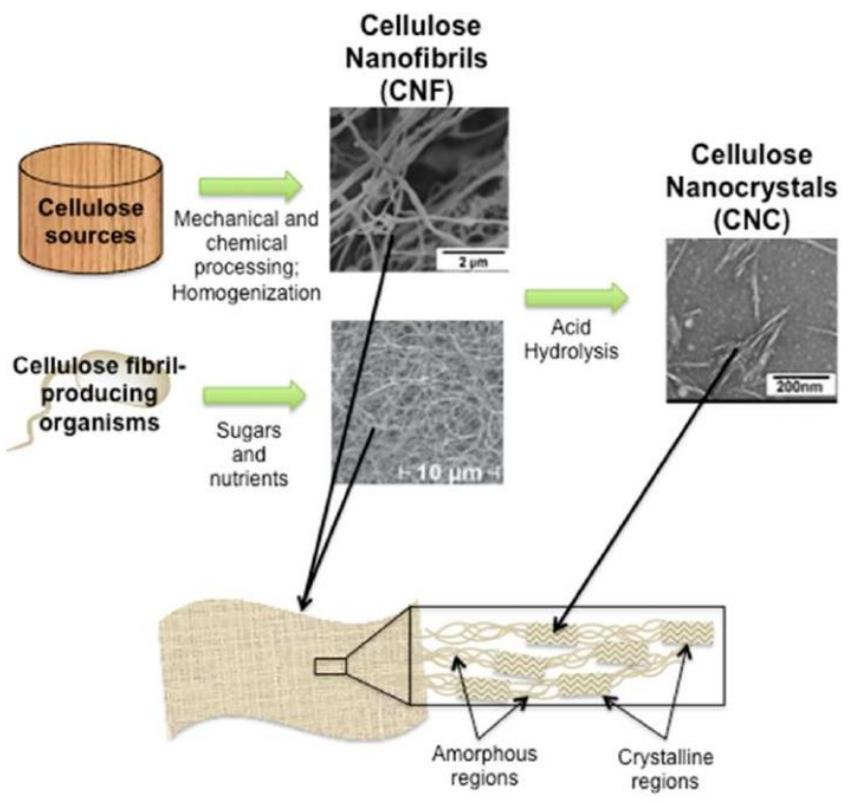

Fig. 2 Acid hydrolysis of cellulose nanofibrils (CNFs) to remove amorphous regions yields cellulose nanocrystals (CNCs). ${ }^{[4]}$ (Copyright 2015, ACS)

CNCs are fabricated by using an acid hydrolysis method. An acidic solution, such as sulfuric acid $\left(\mathrm{H}_{2} \mathrm{SO}_{4}\right)$, is often used to remove the non-crystalline region from fibers. ${ }^{[16]}$ Other acidic chemicals, including hydrochloric, ${ }^{[17]}$ phosphoric, ${ }^{[18]}$ phosphotungstic, ${ }^{[19]}$ and organic acids, ${ }^{[20]}$ have also been used to produce CNCs with different properties. Highly uniform and pure CNCs have dimensions of 100-300 $\mathrm{nm}$ long and 5-70 $\mathrm{nm}$ in diameter depending on the source 
material and isolation method.

As illustrated in Fig. 2, cellulose nanocrystals (CNCs) and cellulose nanofibrils (CNFs) are distinguished by whether the amorphous regions in cellulose are retained during the preparation process. The rod-like CNCs are fabricated through acid hydrolysis of cellulose fibers, which dissolve the amorphous structures between crystalline regions to form $\mathrm{CNCs}$ with a highly crystalline structure. ${ }^{[21,22]}$

\section{Nanocellulose-based aerogels as adsorbents}

An aerogel, in general, is a synthetic porous ultralight material derived from a gel, in which the liquid component for the gel has been replaced with a gas, forming a solid with an extremely low density. ${ }^{[23]}$ Besides other substrate materials, such as silica and carbon, nanocellulose is often used to create aerogels with a robust network structure in terms of interfibrillar hydrogen bonding via a freezing-thawing process. ${ }^{[24,25]}$ Because of the favorable attributes of high porosity, high specific surface area, and tunable surface chemistry, nanocellulose aerogels have been widely applied in water treatment as adsorbing materials and catalyst carriers. ${ }^{[26]}$ The following illustrates the application as adsorbents.

\subsection{Heavy metal ion adsorption}

Flexible and porous nanocellulose aerogels with different loading rates of particles of a metal-organic framework (MOF) were synthesized by Zhu et al. ${ }^{[27]}$ Their work overcame the longstanding challenge of processing MOF particles into a convenient and tailorable form by entrapping them within a cellulose nanocrystal (CNC) aerogel. The hybrid materials are prepared through a water-based sol-gel process, followed by a freeze-drying process. The CNCs individually form a colloidally stable suspension but are assembled into a covalently crosslinked cluster with entrapped MOF particles when mixed together. In the hybrid materials, MOF (such as applications (Fig. 3). The $\mathrm{Cr}(\mathrm{VI})$ contaminated water was UiO-66) particles still retain their crystallinity, porosity, and accessibility in the aerogel format, making them containing ideal adsorbents for water purification used to test the adsorptive capacities. Aerogels without the MOF (control samples) did not show any removal of $\mathrm{Cr}(\mathrm{VI})$ after $24 \mathrm{~h}$. The aerogel containing $50 \mathrm{wt} \%$ of the MOF, adsorbed $85 \%$ of $\mathrm{Cr}(\mathrm{VI})$ after $24 \mathrm{~h}$. The adsorption capability of $\mathrm{Cr}(\mathrm{VI})$ decreased dramatically with
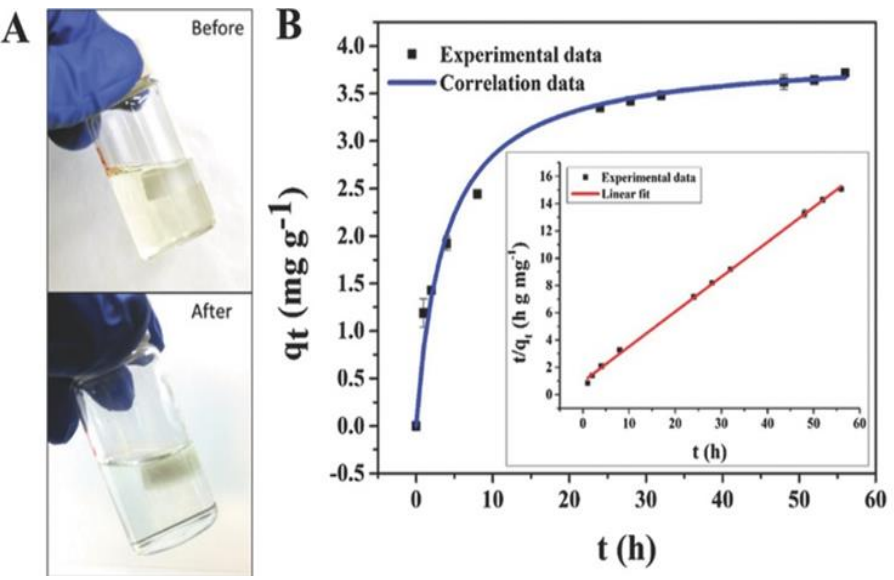

Fig. 3 (A) Photographs of the contaminated aqueous solution before and after adsorbing $\mathrm{Cr}(\mathrm{VI})$ in the aerogel with $50 \mathrm{wt} \%$ UiO-66 and (B) the time dependent adsorption (correlation curve was drawn using the kinetic parameters calculated from the pseudo-second-order model) and pseudosecond-order plots (inset). ${ }^{[27]}$ (Copyright 2016, Wiley)
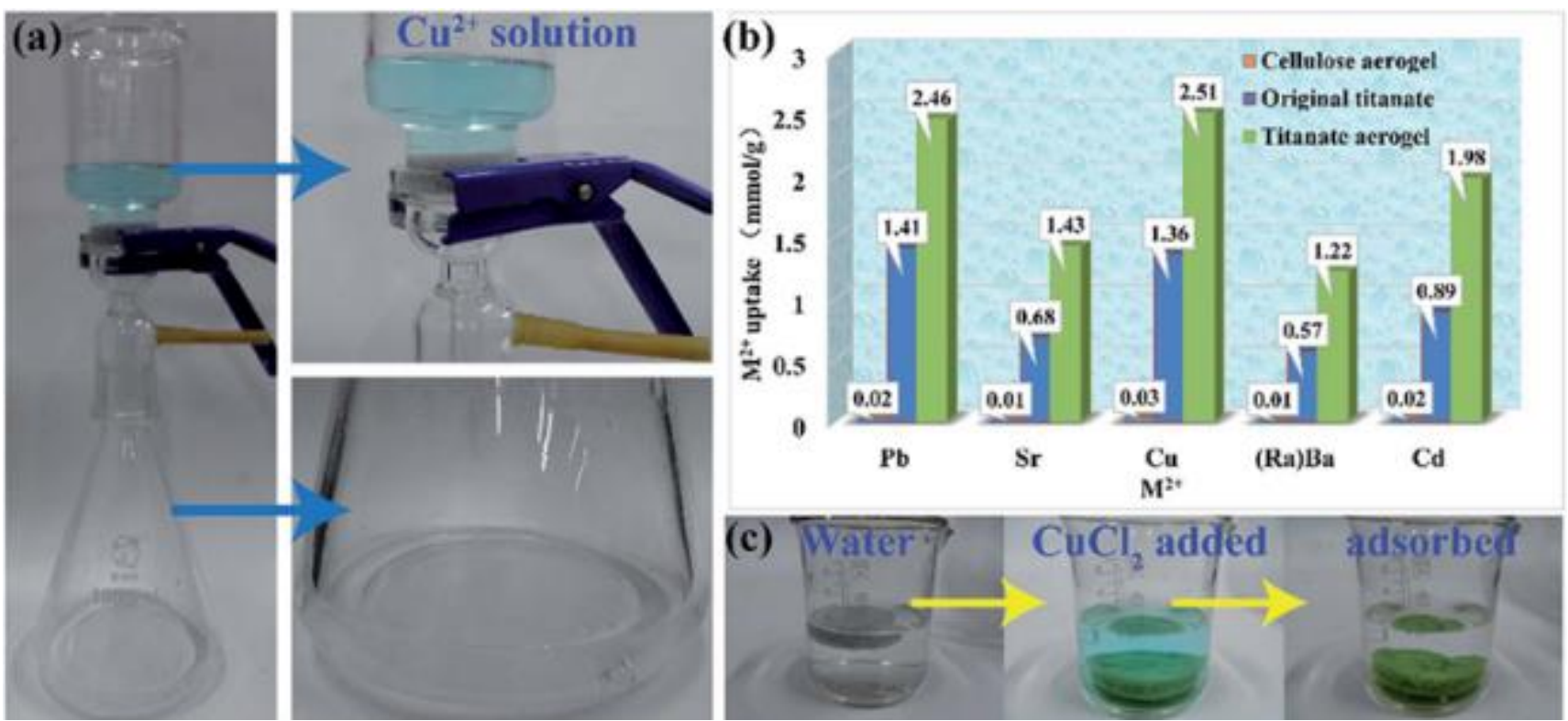

Fig. 4 (a) The apparatus for the high flux toxic cation capture. (b) The $\mathrm{Pb}^{2+}, \mathrm{Sr}^{2+}, \mathrm{Cu}^{2+}, \mathrm{Ra}^{2+}$, and $\mathrm{Cd}^{2+}$ saturated adsorption by the titanate aerogel (green columns), original titanate (blue columns), and pure cellulose aerogel (dark yellow columns). (c) The comparison before and after $\mathrm{Cu}^{2+}$ adsorption. ${ }^{[28]}$ (Copyright 2017, RSC) 


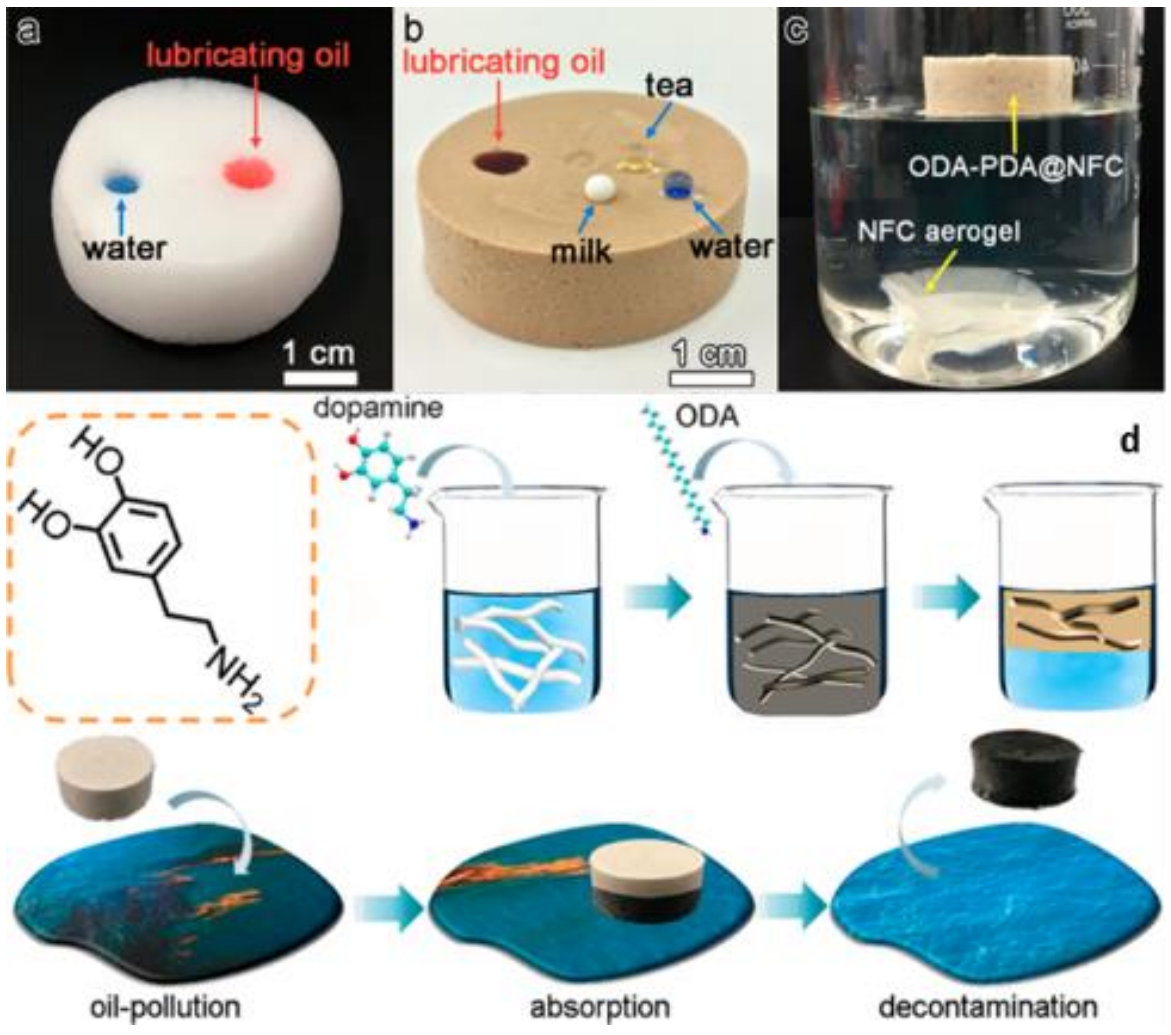

Fig. 5 Behavior of NFC aerogel (a) and ODA-PDA@NFC aerogel (b) toward different liquids and in bulk water (c), Schematic illustration of fabrication of NFC-based aerogels for highly efficient oil/water separation. ${ }^{[29]}$ (Copyright 2018, ACS)

the decrease in the concentration of the MOF. Aerogels with lower MOF loadings (33.3 and $20 \mathrm{wt} \%$ of the MOF) adsorbed $67 \%$ and $51 \%$ of the $\mathrm{Cr}(\mathrm{VI})$, respectively.

Xiong et al. ${ }^{[28]}$ fabricated a 3D titanate aerogel mixed with NFC as an adsorption-aggregator to improve the adsorption efficiency of heavy metal ions in water. A mixed solution consisting of titanate nanofibers and cellulose was frozen and then immersed in a precipitation bath with ethanol solution. Then, a freeze-drying and a vacuum-drying process were carried out to produce the titanate aerogel. The adsorption capacities of $\mathrm{Pb}^{2+}, \mathrm{Sr}^{2+}, \mathrm{Cu}^{2+}, \mathrm{Ra}^{2+}$, and $\mathrm{Cd}^{2+}$ were $2.46,1.43,2.51,1.22$, and $1.98 \mathrm{mmol} / \mathrm{g}$, respectively. The adsorption capacities of these heavy metal ions of titanate aerogel were improved by $70 \%$ to $122 \%$ compared with the original titanate, as shown in Fig. 4. This uniform, multi-grade, porous, cost-efficient 3D network titanate aerogel has several potential applications, such as in sewage disposal and wastewater treatment.

\subsection{Oil-water separation}

Superhydrophobic nanofibrillated cellulose (NFC) aerogels can be used as oil sorbents. Inspired from the chemistry of mussel adhesives, Gao et al. ${ }^{[29]}$ synthesized NFC aerogels with a superhydrophobicity by firstly dipping NFC into a dopamine/octadecylamine (ODA) emulsion to coat the NFC, followed by a freeze-drying process. The formed polydopamine (PDA) surface coating layer acted as an anchor between the NFC scaffold and ODA. The obtained aerogel with a coating layer had an ultralow density of 6.04 $\mathrm{mg} / \mathrm{cm}^{3}$ and a high contact angle of $152.5^{\circ}$, which endowed the aerogel with superb buoyancy and excellent oil/water absorption selectivity (Fig. 5).

NFC/PVA (polyvinyl alcohol) aerogels coated by stearic acid chloride (SAC) also showed a superhydrophobicity. Chhajed et al. ${ }^{[30]}$ fabricated NFC/ PVA aerogels by a freeze-drying process of aqueous NFC/PVA suspension without the use of chemicals. The aerogels were then functionalized through a dip-coating process. The solution was the SAC solution. The SAC conjugated aerogels showed a high porosity of $98 \%$, a superhydrophobicity (i.e., a contact angle of $\sim 159^{\circ}$ ), and an oleophilic property (i.e., a contact angle of $\sim 0^{\circ}$ ). The adsorption capability of the aerogel is measured by the ratio of the weight of liquid adsorbed and dry weight of the aerogel. It was found that the amount of liquid adsorbed was at least 35 times higher than the dry weight. As shown in Fig. 6, the NFC/PVA aerogels demonstrated excellent selectivity and selectivity in separating a series of oil/water mixtures and various organic solvents. The aerogel materials could be easily cleaned up and reused frequently. In the study done by Gong et al. ${ }^{[31]}$ the modification of hydrophobicity of CNCs/PVA aerogels was achieved by using a thermal chemical vapor deposition (CVD) technique. The CNCs/PVA aerogel was prepared by using the freeze-drying process. The CVD technique was used to hydrophobilize the CNCs/PVA aerogels. The potassium carbonate $\left(\mathrm{K}_{2} \mathrm{CO}_{3}\right)$ solution was placed in a 


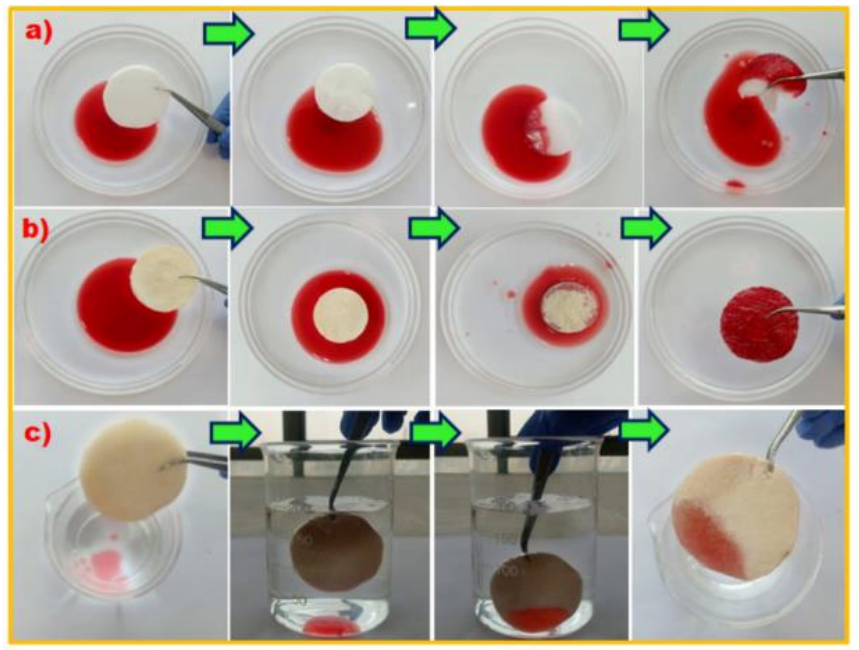

Fig. 6 Oil spillage cleanup; (a and b) from surface water, (diesel engine oil/water mixture) using (a) NFC/PVA aerogel, (b) NFC/PVA-SAC aerogel (c) from underwater system (chloroform/water mixture) using NFC/PVA-SAC aerogel. ${ }^{[30]}$ (Copyright 2019, Elsevier) desiccator which was used for CVD overnight to maintain the relative humidity $(43 \%)$ and methyl trichlorosilane $\left(\mathrm{CH}_{3} \mathrm{Cl}_{3} \mathrm{Si}\right)$ was used for hydrophobic treatment. Their results showed that the aerogels were highly porous (porosity $>97.7 \%$ ) and ultralight with a density ranging from 22.5 to $36.1 \mathrm{mg} / \mathrm{cm}^{3}$ and floatable on the water surface. The wettability test revealed that the aerogel surface was highly hydrophobic with water contact angles up to $144.5^{\circ}$. In comparison to other $\mathrm{CNC}$ reinforced materials that cannot be repeatedly compressed, the cellulose nanocrystals/PVA aerogel can be compressed 50 times without a significant decrease in the compression strength.

Liu et al. ${ }^{[32]}$ summarized the preparation methods, structure, and oil-absorption performance of aerogel-type oil sorbents derived from nanocellulose before 2017. Three major types are NFC-based aerogels, bacterial cellulose (BC)-based aerogels, and nanocellulose-derived carbon aerogels. NFC-based aerogels have superior oil-absorption performance, compression strength, and reusability because of interconnected cellulose nanofibrils forming a porous $3 \mathrm{D}$
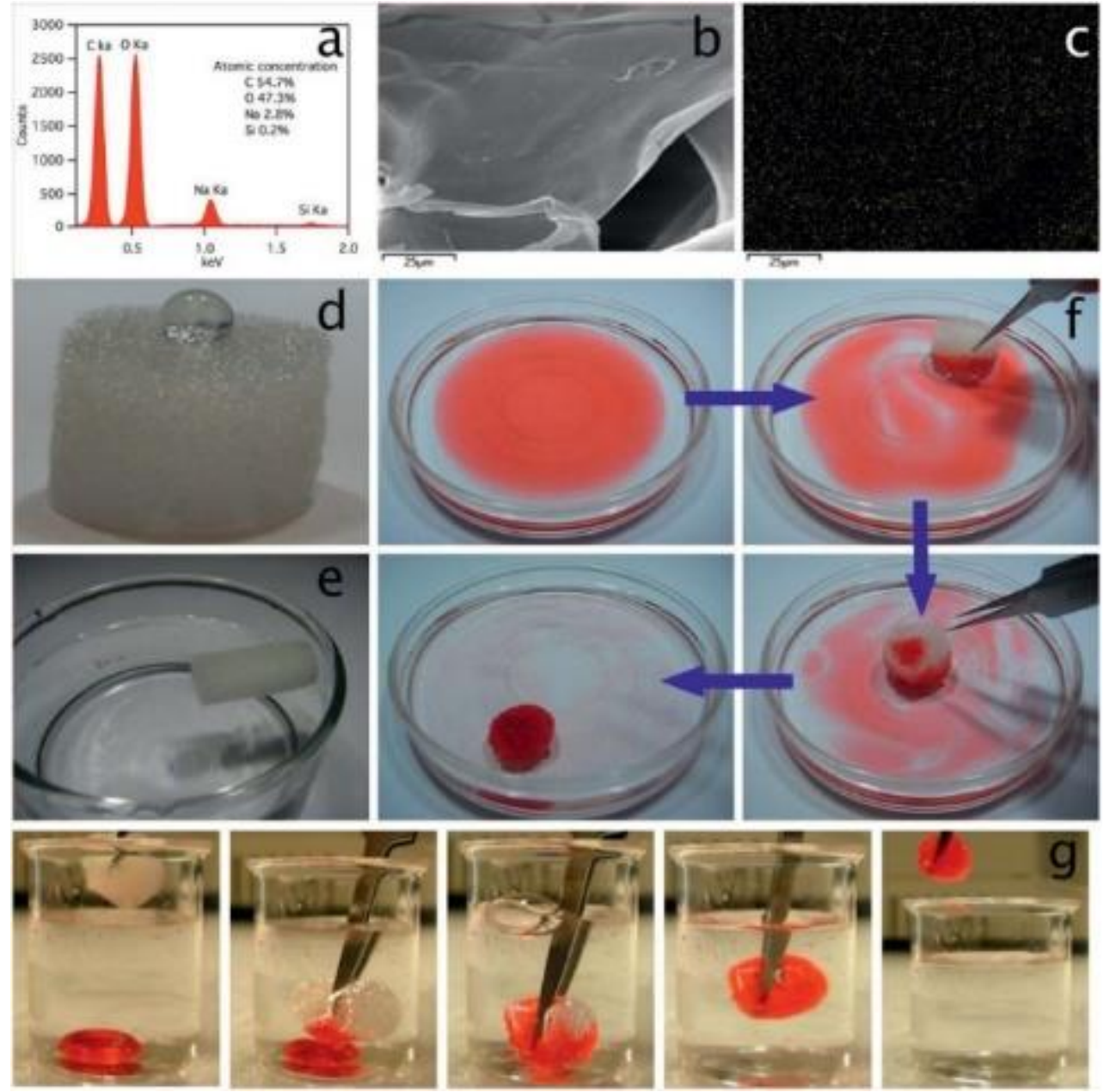

Fig. 7 Triethoxyl(octyl) silane modified 0.2 CNF aerogel: (a) EDS spectrum; (b) SEM image; (c) silicon mapping; (d) photograph of a water droplet on top; (e) photograph of the aerogel floating on water surface without adsorption; sequential snapshots of removing (f) a layer of Sudan IV dyed decane on top of water and (g) Sudan IV dyed chloroform at the bottom of water. ${ }^{[33]}$ (Copyright 2014, RSC) 

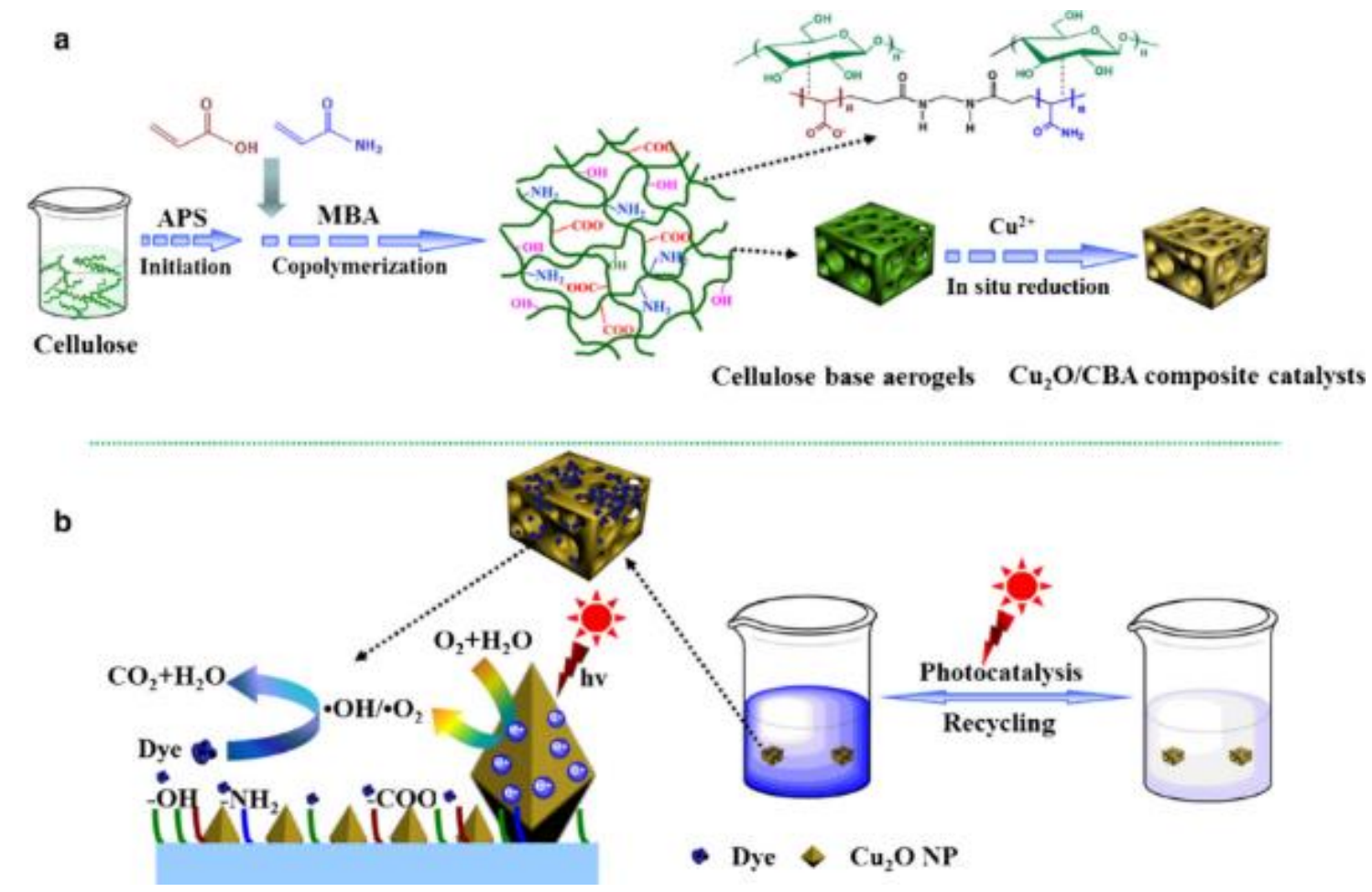

Fig. 8 (a) Schematic for the synthesis of $\mathrm{Cu}_{2} \mathrm{O} / \mathrm{CBA}$ composite catalysts. (b) Photocatalytic degradation of dye by $\mathrm{Cu}_{2} \mathrm{O} / \mathrm{CBA}$ under visible-light irradiation. ${ }^{[34]}$ (Copyright 2017, Springer)

network structure. However, the freezing and water and chloroform compared to the dry weight of the hydrophobization processes of NFC-based aerogels are of aerogel, respectively. It also has the capability of adsorbing high energy demand. In addition, the recovery methods of 139 to 356 times non-polar hydrocarbons, polar aprotic spent aerogels (e.g., vacuum distillation, solvent extraction) solvents and oils, surpassing all previously reported often have low efficiency in terms of time and cost.

\subsection{Dye adsorption}

Jiang et $a .^{[33]}$ produced ultra-light (density of 1.7 to 8.1 $\mathrm{mg} / \mathrm{cm}^{3}$ ) and ultra-porous (porosity of $99.5 \%$ to $99.9 \%$ ) aerogels using CNFs that were defibrillated from rice straws through a freeze-drying process. The CNF aerogels were further modified by exposing them to triethxyl(octyl) silane vapor at $120{ }^{\circ} \mathrm{C}$ for $12 \mathrm{~h}$ under vacuum to reduce its surface hydrophilicity. They found that the CNF aerogels exhibited a super adsorption capacity by adsorbing 210 and 375 times polymeric, cellulosic and carbonaceous aerogels by 2 to nearly 20 times (Fig. 7).

\section{Nanocellulose-based aerogels as catalyst carriers}

Because of the porous structure of nanocellulose-based aerogels and a large number of functional groups on nanocellulose, they are ideal catalyst carriers. For example, Su et $a l^{\left[{ }^{[34]}\right.}$ reported a cellulose-based aerogel (CBA) loaded with $\mathrm{Cu}_{2} \mathrm{O}$ nanoparticles that functioned as a nanoparticles

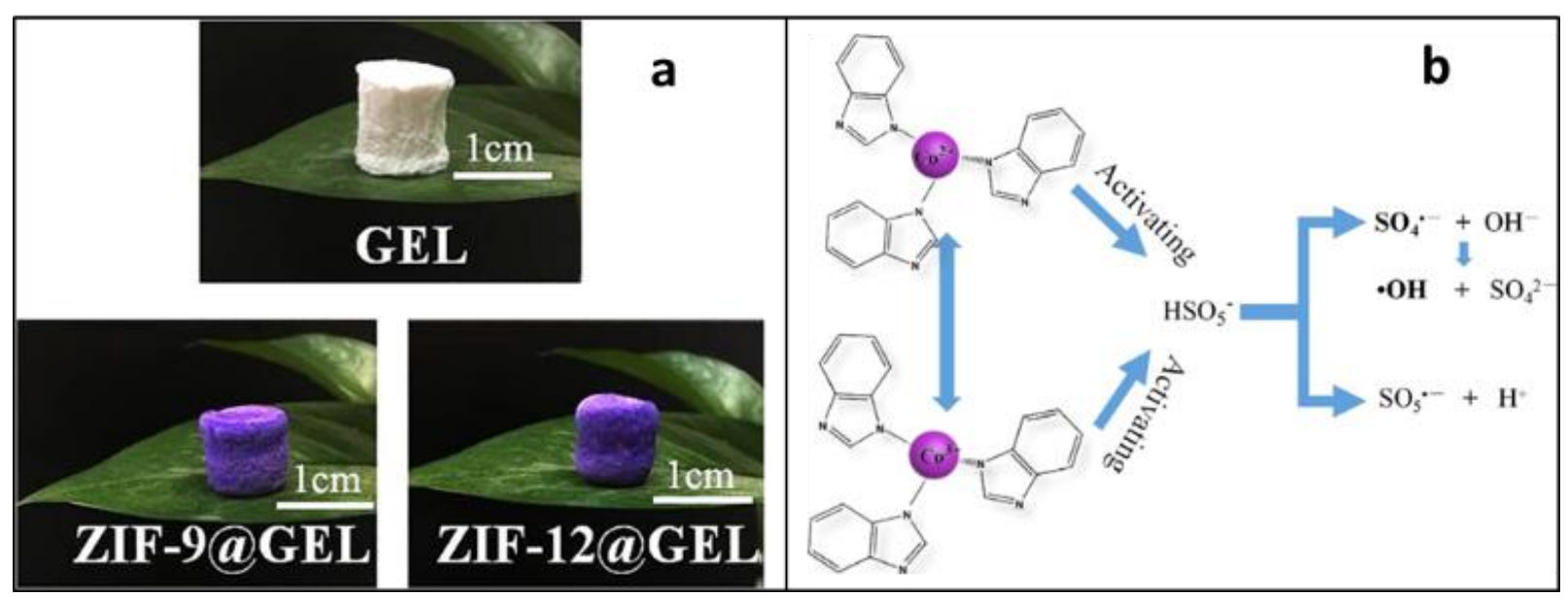

Fig. 9 (a) Photos of pure aerogels and hybrid aerogels. (b) Mechanism schematic of ZIF@GEL/PMS system to generate free radicals. ${ }^{[35]}$ (Copyright 2018, Elsevier) 
were in situ deposited on the surface of macro-size pores of the aerogel through abundant active sites (Fig. 8a). The CBA acted as a microreactor to prevent aggregation and protected the catalytic characteristic of the $\mathrm{Cu}_{2} \mathrm{O}$ nanoparticles. The photocatalytic performance of the $\mathrm{Cu}_{2} \mathrm{O} / \mathrm{CBA}$ composite catalyst was tested by conducting a degradation of methylene blue (MB) test (Fig. 8b). The results showed that the photodegradation rate of $\mathrm{MB}$ by the $\mathrm{Cu}_{2} \mathrm{O} / \mathrm{CBA}$ composite catalyst reached $95.79 \%$, which was about $30 \%$ higher than that of pure $\mathrm{Cu}_{2} \mathrm{O}(73.59 \%)$. The $\mathrm{Cu}_{2} \mathrm{O} / \mathrm{CBA}$ composite catalyst was reusable since the degradation rate of $\mathrm{MB}$ could still retain at approximately $80 \%$ after six cycles of irradiation for $30 \mathrm{~min}$.

A study was done by Ren et al. ${ }^{[35]}$ discussed the fabrication of recyclable metal-organic frameworks (MOFs)/cellulose aerogels that could be used to remove recalcitrant organic contaminants. The MOFs were used as catalysts to activate peroxymonosulfate (PMS) to react with organic contaminants, such as Rhodamine B (RB), tetracycline hydrochloride (TC) and p-nitrophenol (PNP). To achieve the separation of MOFs from the solution, zeolitic imidazole framework (ZIF) materials (ZIF-9 and ZIF-12) were loaded on cellulose aerogels by soaking the MOFs/cellulose aerogels into solutions of ZIF-9 and ZIF-12. The degradation experiment of PNP was carried out. The test results showed that the hybrid aerogels/PMS system could remove approximately $90 \%$ of PNP in $1 \mathrm{~h}$. The aerogel could be easily separated from the solution. The outstanding degradation of PNP demonstrated the promising prospects of this hybrid aerogel as an advanced oxidation process catalyst (Fig. 9).

Ellebracht et al. ${ }^{[36]}$ produced cross-linked acid-based bifunctional catalyst aerogels using TEMPO-oxidized cellulose nanofibrils (TOCNFs) as a substrate. The aerogels were produced via a variety of processing approaches and then freeze-dried from water or tert-butyl alcohol/water mixtures. A finer pore structure and increased surface area (up to $74 \mathrm{~m}^{2} / \mathrm{g}$ ) were achieved when tert-butyl alcohol was used as co-solvent. The stability of solvents of the aerogels was significantly improved due to the formation of a cross-linked structure. The aerogel catalysts were proved to be active acid-base cooperative catalysts for aldol condensation reactions in batch reactions. Continuous flow reactions were performed with glass column reactors packed with aerogel catalysts, and improved rates were shown relative to batch experiments. This study well demonstrated the application of cellulose nanofibril aerogels as catalysts in continuous liquid flow reactions.

\section{Nanocellulose-based membranes}

Nanocellulose membranes are another type of product that can be used to make membranes for sewage treatment. Comparing with CNF based aerogels, nanocellulose membranes are easy-to-fabricate and low cost. The effect of sewage treatment is determined by the pore size of the membrane formed by the interconnected cellulose nanofibrils and a driving force, which could be the gravity force of the liquid (Fig. 10). So far, there have been a lot of studies addressing the fabrications and applications of nanocellulose membranes. Applications related to water treatment include fluoride removal membranes, substrates to remove humic acid, separation of xenotropic murine leukemia virus, and separation of metal ions and dyes. ${ }^{[37-43]}$

Ultrafine CNFs can be fabricated to CNF membrane as an efficient absorbent for the removal of radioactive metals

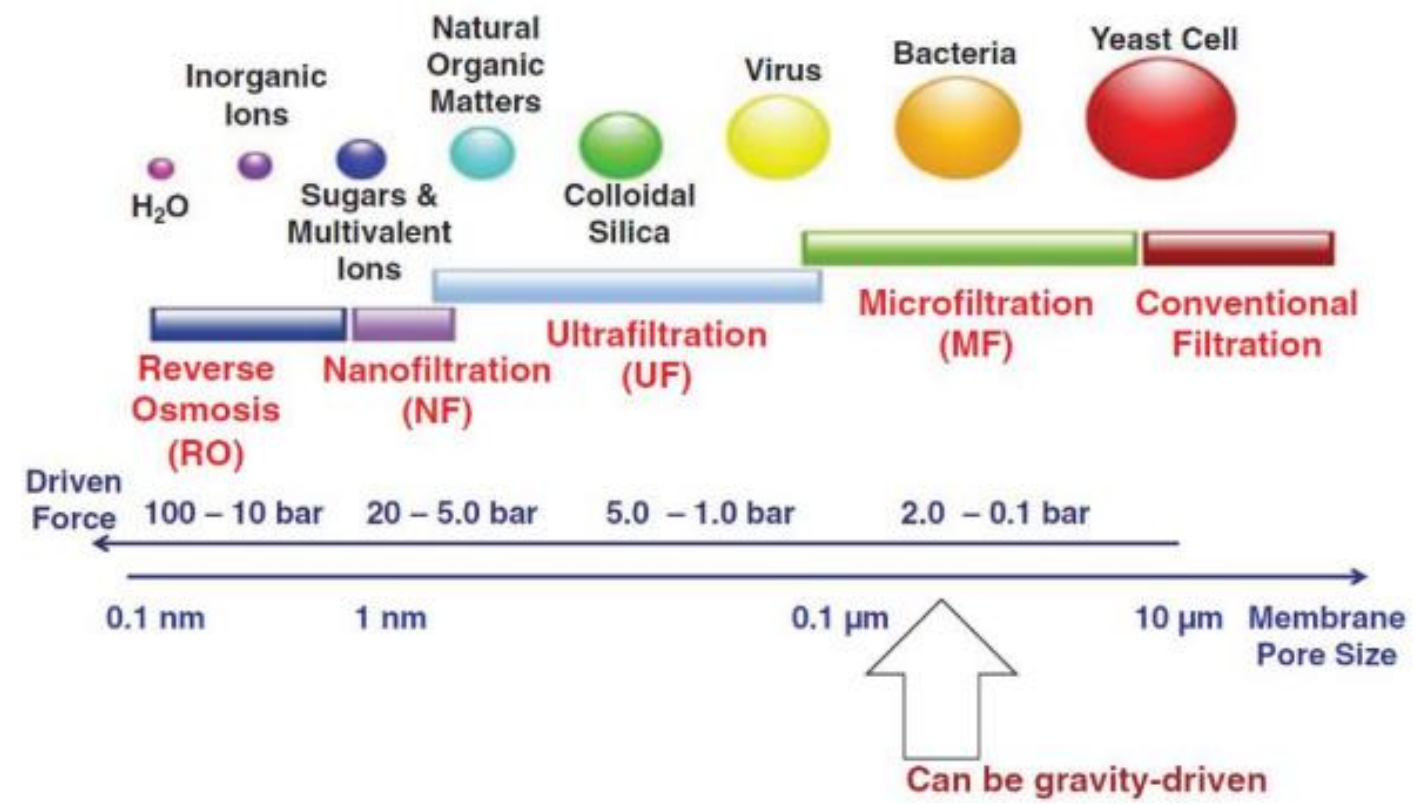

Fig. 10 Classification of pressure-driven membrane filtration, and their pore size and pressure relationship. ${ }^{[43]}$ (Copyright 2020 , Wiley) 
from radio-nuclear wastewater because of the large specific surface area, micro/nanoporous structure, and many cationic functional groups. ${ }^{[44]}$ In the study done by Ma et al., wood pulp was oxidized by (2,2,6,6-tetramethyl piperidin-1-yl) oxyl (TEMPO)/NaBr/NaClO, followed by a mechanical treatment to produce ultrafine cellulose nanofibrils with 5-10 $\mathrm{nm}$ in diameter. The $\mathrm{UO}_{2}^{2+}$ adsorption capability of the ultrafine cellulose nanofibrils was examined, and the result was $167 \mathrm{mg} / \mathrm{g}$.

The wood pulp is pretreated through a reaction with glycidyl trimethylammonium chloride. ${ }^{[45]}$ The CNF made from this pretreated pulp is called surface quaternized cellulose nanofibrils (Q-CNFs). Pei et al. ${ }^{[45]}$ made cellulose nanopaper sheets using Q-CNF aqueous dispersions and found they exhibited an extremely high tensile strength (ca. $200 \mathrm{MPa}$ ) and Young's modulus (ca. $10 \mathrm{GPa}$ ). The porosity of the nanopaper sheets was between $37 \%$ to $48 \%$, so they had a high water absorbency of $750 \mathrm{~g} / \mathrm{g}$ nanopaper, a high surface cationic charge density, and a high anionic dye adsorption capability. The Q-CNFs nanopaper showed great performance to remove organic pollutants (congo red and acid green) in sewage treatment and painting and textile industries. ${ }^{[45]}$

Anionic cellulose nanofibrils (CNFs) adsorbents can be used for an ionizable pharmaceutical, salbutamol. For example, The anionic CNFs were produced from woody cellulose through a succinylation pretreatment in urea- $\mathrm{LiCl}$ deep eutectic solvent (DES), followed by a nanofibrillation procedure. $^{[46]}$ Selkälä et al. ${ }^{[46]}$ fabricated an anionic CNFs adsorbent and examined the adsorption capacity of pharmaceutical agent salbutamol. A maximum adsorption capacity up to $196 \mathrm{mg} / \mathrm{g}$ was obtained. They discussed the potential applications of cellulose nanomaterials as adsorbents and the importance of controlling the charge of adsorbent materials when developing solutions for ionizable micropollutant removal.

In the latest study, Ibrahim et al. ${ }^{[47]}$ investigated novel cellulose/graphene oxide nanosheets (GONSs) as microfiltration (MF) membranes for seawater desalination applications. The GONSs were incorporated into cellulose MF membranes via a vacuum filtrate mixture. The performance of the fabricated membranes was assessed in terms of water flux, bacteria removal, and anti-fouling capabilities. A total bacteria count removal efficiency of 93.6 $\pm 2.4 \%$ and $27.4 \pm 12.5 \%$ was achieved using the cellulose/GONS membranes and control pristine cellulose membranes, respectively. This higher removal efficiency was achieved at a water flux of $334.7 \pm 10.4 \mathrm{~L} /\left(\mathrm{m}^{2} \mathrm{~h}\right)$. This surface modification of MF membranes with anti-fouling nanomaterials has the potential to be implemented in the pretreatment of seawater to improve the reverse osmosis (RO) performance and lower energy consumption.

\section{Wood-based morph genetic materials}

Morph genetic materials are a type of new materials that keep natural biological fine morphology and hierarchical structures and have unique characteristics and functions. Wood has a natural multi-porous, multi-scale hierarchical structure, and is an ideal template for preparing morph genetic materials. In recent years, wood-based composite materials have been widely used in structural construction, energy storage, sensors and environmental management. ${ }^{[48-52]}$ In this review, we will focus on the research studies about the applications of wood-based materials in water treatment.

Wood-based morph genetic synthesis is a technique using bio-structures as templates to fabricate micro-cellular materials. Wood is a great example of a morph-genetic template, which can be used to synthesize carbides like TiC and SiC. ${ }^{[50]}$ Recently, researchers have attempted to use simple chemical treatment methods to make a variety of wood-based composite materials while retaining the wood cellulose framework. ${ }^{[14,53-57]} \mathrm{Hu}$ et al. ${ }^{[58]}$ reported a mesoporous, three-dimensional (3D) wood membrane decorated with palladium nanoparticles (Pd NPs/wood membrane) for efficient wastewater treatment (Fig. 13). By in situ forming Pd NPs within the lumens of wood cells (wood species: basswood), the water treatment rate of the $3 \mathrm{D}$ Pd NPs/wood membrane reached $1 \times 10^{5} \mathrm{~L} \cdot \mathrm{m}^{-2} \cdot \mathrm{h}^{-} 1$ with a high MB removal efficiency $(>99.8 \%) .{ }^{[58]}$

Zhu et al. ${ }^{[59]}$ fabricated superhydrophobic carbon nanotubes (CNTs)/wood aerogel for efficient oil recovery. This CNTs/wood aerogel is different from the abovementioned nanocellulose aerogel materials. The aerogel developed in this study retained the hierarchical structure of natural wood by selectively removed the lignin and hemicellulose, followed by a freeze-drying process. Also, a thermal management function was added to the superhydrophobic aerogel through conducting a chemical vapor deposition (CVD) and novel splicing with CNTs. The lipophilicity of the modified wood aerogel in conjunction with an intrinsic CNT photothermal effect provided an optimal juxtaposition of adsorption, fast volatilization, and accelerated purification characterized by continuous removal of the oil from the aerogel in a gaseous form. ${ }^{[59]}$

An asymmetric wood with a wettability gradient along the wood channels and directional liquid transport property was developed by Luo et al. ${ }^{[60]}$ Raw softwood slices $(1.8 \mathrm{~mm}$ in thickness and $30 \mathrm{~mm}$ in diameter) were first carbonized at $180{ }^{\circ} \mathrm{C}$. Then one face of carbonized wood (CW) slice was treated by spraying polydimethylsiloxane (PMDS) solution with $1 \%$ concentration for several seconds $(3,6,9,12 \mathrm{~s})$. The PDMS coating allowed water molecules pass through it, and thus the face of CW slice coated with PDMS showed super hydrophilicity. The other face of CW slice exhibited superhydrophobicity. Directional liquid transport behavior of the asymmetric CW slice was achieved. The hierarchical microstructures and wettability gradients of the $\mathrm{CW}$ slice results in tunable surface wettability and directional liquid transport property. The CW slice developed can work for liquid water, water vapor and oil, showing a wide application 
in liquid manipulation, water harvest and treatment, etc.

A delignified wood with a cellulose coating layer was developed by Wu et al. ${ }^{[61]}$ Basswood was used as a substrate. A conventional delignified method that employed a sulfite solution or an alkaline solution was used to remove the lignin in basswood samples. The delignified wood was coated by cellulose via the hydrolysis process of cellulose acetate. This material exhibited excellent oil-repellent properties and efficient crude oil/water separation abilities. Excellent anti-oil properties originally came from the chemical structure of cellulose, in which the hydrophilic hydroxyl groups were densely and symmetrically linked to the main chains. Moreover, the cellulose coating allowed the delignified wood to remove oil contamination from its surfaces both in a pre-hydration state and in a dry state while the nascent state only worked well underwater because of remaining impurities, like lignin and hemicellulose. This study demonstrates that the delignified wood with a cellulose coating layer showed great potential in the practical treatment of waste-oil.

\section{Conclusions and perspectives}

Nanocellulose, derived from sustainable and renewable forestry-based biomass, is gaining the increasing interest in being popular bio-based adsorbent because of its fascinating physical and chemical properties, good biocompatibility, anisotropic shape, tailorable surface chemistry, etc. It is expected that this review would deliver some exciting insights regarding the diverse applications in water and oil treatment that can be impacted by this nanocellulose material. In this review, the use of nanocellulose-based composite materials (aerogel, membrane) and morph-genetic wood materials in the wastewater treatment and waste-oil remediation was overviewed. The applications focused on oil-water separation, catalytic degradation of organic pollutants, and adsorption of heavy metal ions and dyes. Most studies have shown promising results in the laboratory scale, indicating great potential in industrial applications.

The major challenges for scale-up applications of aerogels and membranes may exist in the high energy demand of the manufacturing processes of CNFs and CNCs and the freeze-drying process of CNF- and CNC-aerogels, the time-consuming and low-cost-effective regeneration of aerogel type sorbents for reusing them, and the degradation of $\mathrm{CNF} /$ polymer mixed membranes (fouling and cracking). The study of morph-genetic wood materials is in the early stage of research study. The modification process and property consistency of large-size wood samples need to be addressed in the future.

\section{Conflict of interest}

There are no conflicts to declare.

\section{Supporting Information}

Not Applicable.

\section{Acknowledgments}

This project was funded by the U.S. Department of Agriculture's Agricultural Research Service (USDA ARS Agreement No. 58-0204-6-003). It was also supported by the USDA National Institute of Food and Agriculture, McIntire-Stennis (Project No. ME042002).

\section{Reference}

[1] I. S. Arvanitoyannis and T. H. Varzakas, Waste Management Food Ind., 2008, 2, 569-628, ISBN: 9780123736543.

[2] A. Mautner, Polym. Int., 2020, doi: 10.1002/pi.5993.

[3] S. D and V. R, Crimson Publishers, 2018, 4 (5), 564-565, doi: 10.31031/TTEFT.2018.04.000597.

[4] A. W. Carpenter; C. F. o. de Lannoy and M. R. Wiesner, Envir. sci. \& technol., 2015, 49 (9), 5277-5287, doi: 10.1021/es506351r.

[5] J. Cai; W. Xu; Y. Liu; Z. Zhu; G. Liu; W. Ding; G. Wang; H. Wang and Y. Luo, Eng. Sci., 2019, 5, 21-29, doi: 10.30919/es8d669.

[6] S. Li; A. Jasim; W. Zhao; L. Fu; M. Ullah; Z. Shi and G. Yang, ES Mater. Manuf, 2018, 1, 41-49, doi: 10.30919/esmm5f120.

[7] W. L. S. Nieh, Production And Applications Of Cellulose Nanomaterials, 2013, pp 213-214.

[8] D. Klemm; B. Heublein; H. P. Fink and A. Bohn, Angew. Chem. Int. Ed., 2005, 44 (22), 3358-3393 1433-7851, doi: 10.1002/anie.200460587.

[9] R. C. Pettersen, ACS Publications, 1984, doi: 10.1021/ba-1984-0207.ch002.

[10] A. Lif; P. Stenstad; K. Syverud; M. Nydén and K. Holmberg, J. Colloid Interface Sci., 2010, 352 (2), 585-592, doi: 10.1016/j.jcis.2010.08.052.

[11] K. Xhanari; K. Syverud and P. Stenius, J. Dispersion Sci. Technol., 2011, 32 (3), 447-452, doi: 10.1080/01932691003658942.

[12] L. Alves; E. Ferraz and J. Gamelas, Adv. Colloid Interface Sci., 2019, 101994, doi: 10.1016/j.cis.2019. 01994.

[13] J. A. F. Gamelas and E. Ferraz, BioResources, 2015, 10 (4), 6310-6313, doi: 10.15376/biores.10.4.6310-6313.

[14] Z. Chen; H. Zhuo; Y. Hu; H. Lai; L. Liu; L. Zhong and X. Peng, Adv. Funct. Mater, 2020, 1910292 1911616-1910301X, doi: 10.1002/adfm.201910292.

[15] A. Isogai; T. Saito and H. Fukuzumi, Nanoscale, 2011, 3 (1), 71-85, doi: 10.1039/C0NR00583E.

[16] J. Rojas; M. Bedoya and Y. Ciro, Cellulose-Fundamental Aspects And Current Trends, 2015, 8, 193-228, doi: 10.5772/61334.

[17] J. Araki; M. Wada; S. Kuga and T. Okano, Colloids Surf. A Physicochem. Eng. Asp., 1998, 142 (1), 75-82, 0927-7757, doi: 10.1016/S0927-7757(98)00404-X.

[18] S. Camarero Espinosa; T. Kuhnt; E. J. Foster and C. Weder, Biomacromolecules, 2013, 14 (4), 1223-1230, 1525-7797, doi: 10.1021/bm400219u.

[19] Y. Liu; H. Wang; G. Yu; Q. Yu; B. Li and X. Mu, Carbohydr. $\begin{array}{lllll}\text { Polym., } & 2014, & 110 & \text { (1), 415-422, } & \text { doi: }\end{array}$ 10.1016/j.carbpol.2014.04.040.

[20] L. Chen; J. Y. Zhu; C. Baez; P. Kitin and T. Elder, Green Chem.y, 2016, 18 (13), 3835-3843, doi: 10.1039/C6GC00687F.

[21] S. Beck-Candanedo; M. Roman and D. G. Gray, 
Biomacromolecules, 2005, 6 (2), 1048-1054 1525-7797, doi: 10.1021/bm049300p.

[22] F. Jiang; A. R. Esker and M. Roman, Langmuir, 2010, 26 (23), 17919-17925, doi: 10.1021/la1028405.

[23] J. V. Alemán; A. V. Chadwick; J. He; M. Hess; K. Horie; R. G. Jones; P. Kratochvíl; I. Meisel; I. Mita and G. Moad, Pure Appl. Chem., 2007, 79 (10), 1801-1829, doi: 10.1351/pac200779101801.

[24] F. Jiang and Y.-L. Hsieh, J. Mate. Chem. A, 2014, 2 (2), 350-359, doi: 10.1039/C3TA13629A.

[25] M. Pääkkö; J. Vapaavuori; R. Silvennoinen; H. Kosonen; M. Ankerfors; T. Lindström; L. A. Berglund and O. Ikkala, Soft Matter, 2008, 4 (12), 2492-2499, doi: 10.1039/B810371B.

[26] P. Xu; J. Yang; Y. Chen; Y. Li; X. Jia and H. Song, Mate. \& Des., 2019, 183, 108179, doi: 10.1016/j.matdes. 019.108179.

[27] H. Zhu; X. Yang; E. D. Cranston and S. Zhu, Adv. Mater., 2016, 28 (35), 7652-7657 \%@ 0935-9648, doi: 10.1002/adma.201601351.

[28] Y. Xiong; C. Wang; H. Wang; Q. Yao; B. Fan; Y. Chen; Q. Sun; C. Jin and X. Xu, J. Mater. Chem. A, 2017, 5 (12), 5813-5819, doi: 10.1039/C6TA10638B.

[29] R. Gao; S. Xiao; W. Gan; Q. Liu; H. Amer; T. Rosenau; J. Li and Y. Lu, ACS Sustain. Chem. \& Eng., 2018, 6 (7), 9047-9055, doi: 10.1021/acssuschemeng. b01397.

[30] M. Chhajed; C. Yadav; A. K. Agrawal and P. K. Maji, Carbohydr. Polym., 2019, 226, 115286, 110144-18617, doi: 10.1016/j.carbpol.2019.115286.

[31] X. Gong; Y. Wang; H. Zeng; M. Betti and L. Chen, ACS Sustain. Chem. \& Eng., 2019, 7 (13), 11118-11128, doi: 10.1021/acssuschemeng.9b00066.

[32] H. Liu; B. Geng; Y. Chen and H. Wang, ACS Sustain. Chem. \& Eng, 2017, 5 (1), 49-66, doi: 10.1021/ cssuschemeng.6b02301.

[33] F. Jiang and Y.-L. Hsieh, J. Mater. Chem. A, 2014, 2 (18), 6337-6342, doi: 10.1039/C4TA00743C.

[34] X. Su; Q. Liao; L. Liu; R. Meng; Z. Qian; H. Gao and J. Yao, Cellulose, 2017, $24 \quad$ (2), 1017-1029, doi 10.1007/s10570-016-1154-0.

[35] W. Ren; J. Gao; C. Lei; Y. Xie; Y. Cai; Q. Ni and J. Yao, Chem. Eng. J., 2018, 349, 766-774, doi: 10.1016 j.cej.2018.05.143.

[36] N. C. Ellebracht and C. W. Jones, Carbohydr. Polym., 2020, 233, 115825, doi: 10.1016/j.carbpol. 019.115825.

[37] D. A. Gopakumar; D. Pasquini; M. A. Henrique; L. C. de Morais; Y. Grohens and S. Thomas, ACS Sustain. Chem. \& Eng., 2017, 5 (2), 2026-2033, doi: 10.1016/j. arbpol.2019.115825.

[38] H. Sehaqui; B. Michen; E. Marty; L. Schaufelberger and T. Zimmermann, ACS Sustain. Chem. \& Eng., 2016, 4, 4582-4590, doi: 10.1021/acssuschemeng.6b00698.

[39] Z. Karim; M. Hakalahti; T. Tammelin and A. P. Mathew, RSC $a d v$, 2017, 7 (9), 5232-5241, doi: 10.1039/C6RA25707K.

[40] Z. Karim; A. P. Mathew; M. Grahn; J. Mouzon and K. Oksman, Carbohydr. Polym., 2014, 112, 668-676, doi: 10.1016/j.carbpol.2014.06.048

[41]Z. Karim; S. Claudpierre; M. Grahn; K. Oksman and A. P. Mathew, J. Membr. Sci., 2016, 514, 418-428, doi: 10.1016/j.memsci.2016.05.018.
[42] M. Asper; T. Hanrieder; A. Quellmalz and A. Mihranyan, Biologicals, 2015, $43 \quad$ (6), 452-456, doi: 10.1016/j.biologicals.2015.08.001.

[43] P. Sharma; S. Sharma; T. Lindström and B. Hsiao, Adv. Sustain. Syst. 2020, 4 (5), 2366-7486, doi: 10.1002/adsu.201900114.

[44] H. Ma; B. S. Hsiao and B. Chu, ACS Macro Lett., 2012, 1 (1), 213-216, doi: 10.1021/mz200047q.

[45] A. Pei; N. Butchosa; L. A. Berglund and Q. Zhou, Soft Matter, 2013, 9 (6), 2047-2055, doi: 10.1039/ 2SM27344F.

[46] T. Selkälä; T. Suopajärvi; J. A. Sirviö; T. Luukkonen; G. S. Lorite; S. Kalliola; M. Sillanpää and H. Liimatainen, Chem. Eng. J., 2018 , 350, 378-385, doi: 10.1016/j.cej.2018.05.163.

[47] Y. Ibrahim; F. Banat; A. F. Yousef; D. Bahamon; L. F. Vega and S. W. Hasan, J. Chem. Technol \& Biotechnol., 2020, 95 (7), 1915-1925, doi: 10.1002/jctb.6341.

[48]D. Zhang; B. Sun and T. Fan, Sci. China Ser. E-Technol. Sci., 2004, 47 (4), 470-478, doi: 10.1360/03ye0541.

[49] D. Zhang; T. X. Fan; B. H. Sun; T. C. Wang; X. Q. Xie and T. Okabe, Mater. Sci. Forum, Trans Tech Publ: 2005, 502, 373-378, doi:10.4028/www.scientific.net/MSF. 02.373.

[50] D. Zhang; T. X. Fan; J. J. Gu; B. H. Sun; T. C. Wang and G. D. Zhang, Key Eng. Mater, Trans Tech Publ: 2006, 313, 7-12, doi:10.4028/www.scientific.net/KEM. 13.7.

[51]S. Liang; Y. H. Li and C. Zhang, Adv. Mater. Res., Trans Tech Publ: 2014, 1010-1012, 207-210. doi:10.4028/www.scientific. net/AMR.1010-1012.207.

[52] X. Wang; X. Zeng and D. Cao, Eng. Sci, 2018, 1, 55-63, doi: 10.30919/es. 180325 .

[53] H. Liu; C. Chen; H. Wen; R. Guo; N. A. Williams; B. Wang; F. Chen and L. Hu, J. Mater. Chem. A, 2018, 6 (39), 18839-18846, doi: 10.1039/C8TA05924A.

[54]S. He; C. Chen; Y. Kuang; R. Mi; Y. Liu; Y. Pei; W. Kong; W. Gan; H. Xie and E. Hitz, Energy \& Environ. Sci., 2019, 12 (5), 1558-1567, doi: 10.1039/ 9EE00945K.

[55] T. Li; H. Liu; X. Zhao; G. Chen; J. Dai; G. Pastel; C. Jia; C. Chen; E. Hitz and D. Siddhartha, Adv. Funct. Mater., 2018, 28 (16), 1707134, doi: 10.1002/adfm. 01707134

[56]C. Wan; Y. Jiao; S. Wei; X. Li; W. Tian; Y. Wu and J. Li, ACS appl. mater. \& interfaces, 2019, 11 (51), 47846-47857, doi: 10.1021/acsami.9b13686.

[57] K. Wang; X. Liu; Y. Tan; W. Zhang; S. Zhang and J. Li, Chem. Eng. J., 2019, 371, 769-780, doi: 10.1016/j.cej.2019.04.108.

[58] F. Chen; A. S. Gong; M. Zhu; G. Chen; S. D. Lacey; F. Jiang; Y. Li; Y. Wang; J. Dai and Y. Yao, Acs Nano, 2017, 11 (4), 4275-4282, doi: 10.1021/acsnano.7b01350.

[59] Z. Zhu; S. Fu and L. A. Lucia, ACS Sustain. Chem. \& Eng., 2019, 7 (19), 16428-16439, doi: 10.1021/cssuschemeng. 9b03544.

[60] Y.-Q. Luo; F. Song; C. Xu; X.-L. Wang and Y.-Z. Wang, Chem. Eng. J., 2020, 383, 123168, doi: 10.1016/j.cej.2019.123168.

[61] M.-B. Wu; Y.-M. Hong; C. Liu; J. Yang; X.-P. Wang; S. Agarwal; A. Greiner and Z.-K. Xu, J. Mater. Chem. A, 2019, 7 (28), 16735-16741, doi: 10.1039/C9TA04913D. 


\section{Author information Biographies}

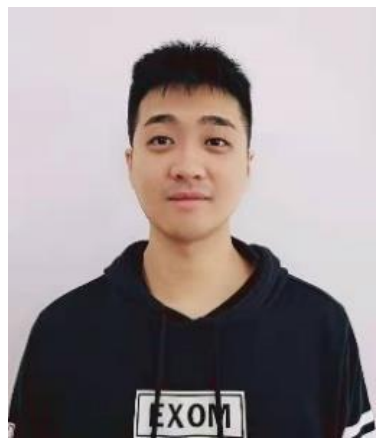

Bingnan Yuan is a Ph.D. candidate in the College of Materials Science and Technology at Northeast Forestry University (NEFU) of China and currently visiting scholar at the University of Tennessee. His research focuses on cellulose-based functional materials and wood surface functional modification.

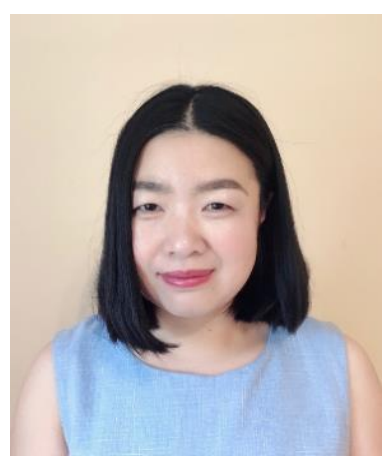

Dr. Ling Li currently an Assistant Professor of Sustainable Bioenergy Systems at the School of Forest Resources (SFR) of the University of Maine (UMaine, USA), obtained a Forestry Engineering Ph.D. degree from the University of $\mathrm{New}$ Brunswick (UNB, Canada, 2014) and received four-year (2014-2018) postdoctoral research experience at the UNB'S Wood Science and Technology Center. Dr. Li directs the Bioenergy Laboratory at the SFR of UMaine. Her research interests focus on advanced technologies to improve the energy efficiency of energy-intensive wood industry and timber-based building sector, innovative carbon-neutral bioproducts, such as engineered wood products and mass timber panel products; numerical analysis of hygrothermal behavior of wood and engineered wood products, and utilization of sustainable biomass as bioenergy resources.

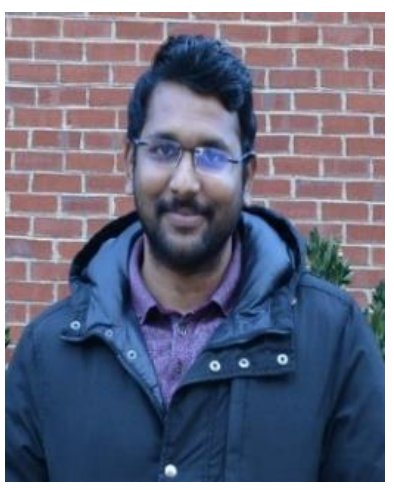

Dr. Vignesh Murugadoss recently completed his Ph.D. degree from Pondicherry University, India. He carried out his Indo-US Bhaskara Advanced Solar Energy (BASE) Internship at the University of Tennessee, USA. His research interests focus on advanced functional materials for sustainable energy and environmental applications.

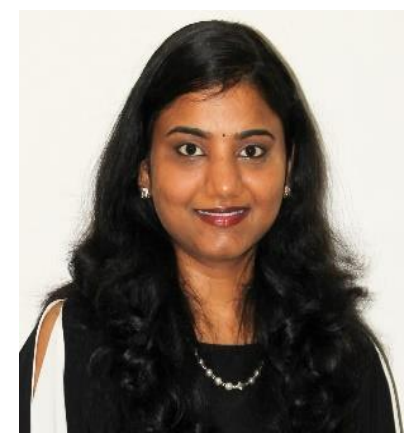

Dr. Sravanthi Vupputuri is a Biomedical Data Scientist in the Clinical Analytics department at the Saint Luke's Health System in Kansas City. Dr. Vupputuri earned her Ph.D. and master's in chemical engineering from Oklahoma State University (2014) and Lamar University (2008), respectively. Her Ph.D. research was focused on designing hybrid nanocarriers for drug and gene delivery. Special emphasis was placed on designing carriers that avoid immune inactivation, target specific cells, and transport the drug or gene into the target cell. Dr. Vupputuri's research interests center on traditional chemical engineering topics and biomedical applications. Her current research interests are in biomedical analytics, bioinformatics, polymer nanocomposites, biomaterials, bio-nano engineering, nano-kinetics, and dielectric materials. Dr. Vupputuri has been published her research in various peer-reviewed journals and an active reviewer for numerous peer-reviewed journals.

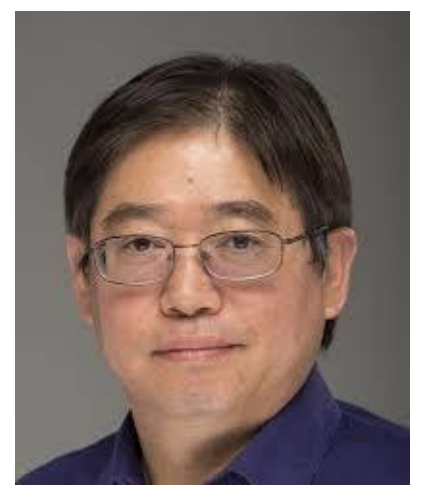

Dr. Jinwu Wang is a Research Forest Products Technologist at the Forest Products Laboratory, USDA Forest Service and a faculty associate at the University of Maine School of Forest Resources and Advanced Structures and Composites Center. His duty is to improve the value of wood and woody biomass through engineered composites science that contributes to the conservation and productivity of the forest resource. He received his B.S. degree from Nanjing Forestry University, M.S. from the University of California at Berkeley, and Ph.D. from Washington State University. He was the recipient of the Wood Award and Outstanding Student Award from the Forest Products Society and its local chapter and the Student Poster Award and George Marra Awards from the International Society of Wood Science and Technology. His current research focus is on bioproducts and biocomposites from woody biomass. 


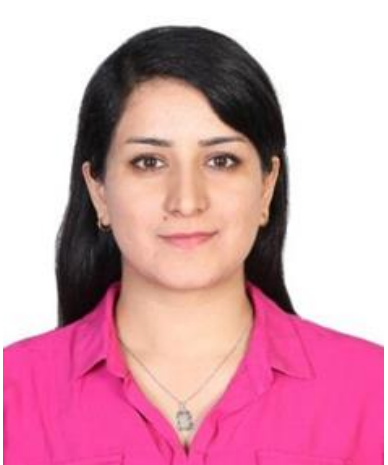

Ms. Nasim Alikhani is a PhD student in the School of Forest Resources at the University of Maine. Her research focuses on the study of moisture selective membrane-based dehumidification system to improve the energy efficiency of kiln-drying processes.

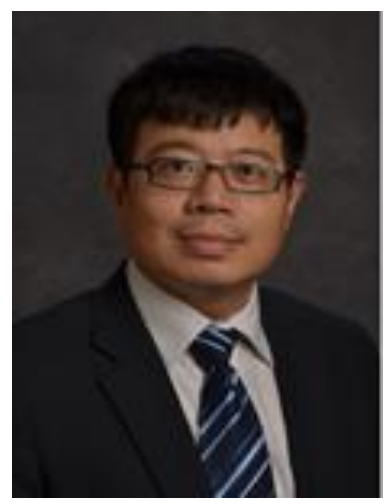

Dr. Zhanhu Guo currently an Associate Professor of Chemical and Biomolecular Engineering at the University of Tennessee, obtained a Chemical Engineering Ph.D. degree from Louisiana State University (2005) and received three-year (2005-2008) postdoctoral training in the Mechanical and Aerospace Engineering Department in University of California Los Angeles. Dr. Guo directs the Integrated Composites Laboratory and chaired the Composite Division of the American Institute of Chemical Engineers (AIChE, 2010-2011). His current research focuses on multifunctional nanocomposites for anti-corrosion, energy harvesting, electronic devices, environmental remediation, fire retardancy, and electromagnetic radiation shielding/absorption applications.

Publisher's Note: Engineered Science Publisher remains neutral with regard to jurisdictional claims in published maps and institutional affiliations. 